\title{
Socio-Demographic Profiles of Naive HIV Pregnant Women and Retention to the Prevention of Mother-to-Child Transmission (PMTCT) Interventions in the East Region of Cameroon
}

\author{
Ottop F. Manyi ${ }^{1}$, Assob N. Jules Clement ${ }^{1}$, Mbu R. Enow ${ }^{2,3}$, Ngowe N. Marcelin ${ }^{4,5}$ \\ ${ }^{1}$ Department of Medical Laboratory Sciences, Faculty of Health Sciences, University of Buea, Buea, Cameroon \\ ${ }^{2}$ Department of Obstetrics and Gynecology, Faculty of Medicine and Biomedical Sciences, University of Yaoundé 1, Yaoundé, Cameroon \\ ${ }^{3}$ Department of Family Health, Ministry of Public Health, Yaoundé, Cameroon \\ ${ }^{4}$ Department of Surgery, Faculty of Medicine and Biomedical Sciences, University of Yaoundé 1, Yaoundé, Cameroon \\ ${ }^{5}$ Faculty of Health Sciences, University of Buea, Buea, Cameroon \\ Email: juleclement@yahoo.fr
}

How to cite this paper: Manyi, O.F., Clement, A.N.J., Enow, M.R. and Marcelin, N.N. (2020) Socio-Demographic Profiles of Naive HIV Pregnant Women and Retention to the Prevention of Mother-to-Child Transmission (PMTCT) Interventions in the East Region of Cameroon. World Journal of AIDS, 10, 36-45.

https://doi.org/10.4236/wja.2020.101004

Received: January 8, 2020

Accepted: March 21, 2020

Published: March 24, 2020

Copyright $\odot 2020$ by author(s) and Scientific Research Publishing Inc. This work is licensed under the Creative Commons Attribution International License (CC BY 4.0).

http://creativecommons.org/licenses/by/4.0/

(c) (i) Open Access

\begin{abstract}
Background: At enrolment into antenatal care, socio-demographic data of HIV infected pregnant women and lactating mothers are usually collected with little or no analysis done on them. This study was aimed to describe the socio-demographic profiles of naive to antiretroviral therapy (ART) HIV-infected pregnant women in the East region of Cameroon and to link this to retention in order to optimize the implementation of the prevention of mother-to-child transmission (PMTCT) interventions. Methods: A descriptive prospective study that lasted from February 2018 until February 2019 in three catchment health facilities in the East region for the recruitment and follow-up of participants who were consented HIV-infected pregnant women naive to ART. Socio-demographic, treatment compliance and adherence data were obtained by healthcare providers who were trained using a standard questionnaire that was conceived, tested and adapted for the study. Data were analyzed using Graph Prism (Graph pad 6.0, San Diego, USA). The Fisher exact and Chi-squared tests were used to establish the associations and independence between different variables at statistical significance level of $p<0.05$. Results: A total of seventy (70) women were enrolled with age range varying between 15 and 40 years with a mean age of $26.5 \pm 6.2$ years. Loss-to-follow-up (LTFU) was observed among 17 women (24.29\%). The Muslim religion, education below secondary level and the profession of housewife were signifi-
\end{abstract}


cantly associated with LTFU at $p=0.01, p<0.0001$ and $p=0.0053$, respectively. For participants who were retained until study endpoint, having secondary level of education or above and a profession other than housewife had a significant association $(p=0.0063)$, as well as being a Christian. Conclusion: Loss to follow-up in PMTCT program was associated with Muslim religion, primary level of education and the housewife occupation.

\section{Keywords}

Pregnant Women, Intervention, Profile, Education, Religion

\section{Background}

HIV/AIDS has had a tremendous impact on global morbidity and mortality of women of child-bearing age and children below 15 years of age [1] [2]. Several efforts have been undertaken globally by Governments, non-governmental organizations (NGOs) and other sectors in a bit to curb this tendency and meet the UNAIDS objectives 90, 90, 90 by 2020. Howbeit, in 2018, 4.49\% (1.7 million) of the estimated 37.9 million people living with HIV globally were children between the ages $0-14$ years [3]. Over 95\% of paediatric HIV infections result from mother-to-child transmission (MTCT) which can occur during pregnancy, labour, delivery or during the postpartum from breastfeeding [4]. The rate of MTCT of HIV varies between $20 \%$ to $45 \%$, with $15 \%$ to $30 \%$ transmission risk in utero or at delivery, and $5 \%$ to $20 \%$ risk through breastfeeding. The overall transmission risk is approaching $30 \%$ to $60 \%$ in Low- and Middle-Income Countries (LMIC) [5] [6]. The risk of MTCT can be reduced to lesser than 2\% by interventions that include antiretroviral (ARV) prophylaxis or treatment given to women during pregnancy and labour and to the infant in the first weeks of life. Other measures include enhanced delivery techniques, and complete avoidance of breastfeeding [5].

Cameroon, one of the 22 PMTCT priority countries, adopted in 2012 the World Health Organization (WHO) option B+ strategy to prevent mother-to-child transmission of HIV. Here, all HIV+ pregnant women and lactating mothers are placed on ART irrespective of their clinical stage and their newborns on nevirapine (NVP) prophylaxis as from birth. For HIV infected women, such treatment modality reduces maternal mortality and morbidity and is known to be the most effective method of preventing MTCT of HIV. It secures the health of the infected woman and improves the chances of survival of her child. Thus, the survival of the mother is a strong predictor of the child's survival [7] [8].

However, irrespective of the great achievements obtained in the diagnosis and ARV coverage worldwide, in Africa, a disturbing pattern of loss-to-follow-up (LTFU) has emerged at each stage of the PMTCT "treatment cascade." A 2004 study in South Africa showed a loss-to-follow-up rate of $85 \%$ at 12 months by HIV-exposed infants [9] [10]. Data from Malawi in 2005 showed cumulative 
loss-to-follow-up rates of $55 \%$ as early as the 36 th week of pregnancy, $68 \%$ at delivery, $70 \%$ at first postnatal visit, and $81 \%$ at 6 -month postnatal visit in rural district hospitals [11]. Also, a systematic review in 2018 reported pooled estimates of retention in care of $72.9 \%$ (95\% CI: $66.4 \%, 78.9 \%$ ) at 6 months for studies reporting $<12$ months of follow up and $76.4 \%$ (95\% CI: 69.0\%, 83.1\%) at 12 months for studies reporting $\geq 12$ months of follow up [12].

All the LTFU cases have been attributed, in most reports, to a failure in the health system, with none, to the HIV+ woman and/or her lifestyle. Considering the fact that at ART initiation or enrolment, socio-demographic data are being collected. This study was aimed at determining the effect of maternal socio-demographic characteristics on their retention in PMTCT interventions in Eastern Cameroon.

\section{Methods}

\subsection{Study Site and Population}

This study was carried out at the Bertoua (Mokolo 1 Integrated Health Centre and Bertoua Regional Hospital) and Garoua Boulai (Gado Badzere Integrated Health Centre) Health Districts, in the East Region of Cameroon. The population included naive to highly active antiretroviral therapy (HAART) HIV infected pregnant women who accepted to be initiated on HAART, attending antenatal care (ANC) visits and were to deliver at study sites.

\subsection{Participant Recruitment and Sampling}

This was a prospective observational multi-centric cohort study involving all voluntary ART-naive HIV-infected pregnant women from February 2018 to February 2019 who accepted to be placed on ART, attending ANC visits and was to deliver at their respective catchment sites. Sampling was by convenience of occurrence to minimize issues of stigmatization and discrimination. Sample size of this study was obtained using the formula for calculating sample size for descriptive studies, that is,

$$
N=\left[Z_{\alpha}^{2} p(1-p)\right] / W^{2} .
$$

where $Z_{\alpha}=1.96, p$ (prevalence of HIV in pregnant women in East region of Cameroon $)=5.6 \%, \alpha$ (type I error $)=5 \%$ and $\mathrm{W}($ confidence interval $)=0.05$.

Participants were recruited after submitting signed informed consent forms. They were assisted to fill structured questionnaires to obtain socio-demographic data, placed on ART and then follow-up until 6 weeks postpartum (See appendices 1 and 2). Clinically, data was captured which were rather used as criteria for exclusion, should a participant be diagnosed of any. The questionnaires, designed by study investigators, were tested and validated one month prior to effective start of study. The participants were excluded if they were known HIV infected pregnant women on HAART, refused to sign the informed consent form or having known comorbidities. 


\subsection{Statistical Analysis}

Data obtained from the questionnaires were entered and managed using Microsoft Excel spreadsheets then, imported to Graph Prism (Graph pad 6.0, San Diego, USA) prior to analyses. All analyses were stratified into "retained in care" or "lost to follow-up (LTFU)". The mean ( \pm standard deviation) for continuous characteristics (such as age) and the frequency of categorical characteristics (such as marital status) were described for the study participants. The Fisher exact and Chi - square tests were used to evaluate associations and statistical significance of the distribution of the outcome among the different variables. Differences were considered significant when $p<0.05$.

\section{Results}

\subsection{Study Participant Characteristics}

Seventy women were enrolled into the study with characteristics as detailed in Table 1. Patients were stratified according to the Health District of their catchment sites. Those from the Bertoua Health District were generally similar to those from the Garoua Boulai Health District regarding their age and marital status. However, a significant difference was found between participants from these health districts as per their occupation, educational system, educational level and religion $(p=0.0069,<0.0001,<0.0001$ and $<0.0001)$ respectively.

\subsection{Retention in Care and Factors Associated}

The impact of maternal socio-demographic data and retention in care are as described in Table 2 . There was $75.71 \%$ retention in care. Religion (Muslim),

Table 1. Characteristics of study participants.

\begin{tabular}{|c|c|c|c|c|c|}
\hline & & $\begin{array}{c}\text { Bertoua } \\
\%(n)\end{array}$ & $\begin{array}{c}\text { Garoua Boulai } \\
\%(n)\end{array}$ & $\begin{array}{l}\text { Total } \\
\%(n)\end{array}$ & $P$-value \\
\hline women & & $82.9(58)$ & $17.1(12)$ & $100(70)$ & - \\
\hline Age (years \pm SD) & & $26.9 \pm 5.9$ & $24.2 \pm 7.3$ & $26.5 \pm 6.2$ & 0.1838 \\
\hline \multirow[b]{2}{*}{ Matrimonial status } & Married & $69(40)$ & $100(11)$ & $73.9(51)$ & \multirow[b]{2}{*}{0.0549} \\
\hline & Single & $31(18)$ & $0(0)$ & $26.1(18)$ & \\
\hline \multirow{2}{*}{ Occupation } & Housewife & $44.8(26)$ & $90.9(10)$ & $52.2(36)$ & \multirow{2}{*}{0.0069} \\
\hline & Others & $55.2(32)$ & $9.1(1)$ & $47.8(33)$ & \\
\hline \multirow{2}{*}{$\begin{array}{l}\text { Educational sys- } \\
\text { tem }\end{array}$} & Islamic & $5.2(3)$ & $63.6(7)$ & $14.5(10)$ & \multirow{2}{*}{$<0.0001$} \\
\hline & Conventional & $94.8(55)$ & $36.6(4)$ & $85.5(59)$ & \\
\hline \multirow{2}{*}{ Educational level } & Primary & $36.2(21)$ & $100(11)$ & $46.4(32)$ & \multirow{2}{*}{$<0.0001$} \\
\hline & Secondary & $63.8(37)$ & $0(0)$ & $53.6(37)$ & \\
\hline \multirow{2}{*}{ Religion } & Christian & $82.8(48)$ & $0(0)$ & $69.6(48)$ & \multirow{2}{*}{$<0.0001$} \\
\hline & Muslim & $17.2(10)$ & $100(11)$ & $30.4(21)$ & \\
\hline
\end{tabular}

Some totals may not sum up to 70,58 or 12 because of missing data. 
Table 2. Impact of maternal sociodemographic characteristics on retention in PMTCT programme.

\begin{tabular}{|c|c|c|c|c|c|}
\hline \multicolumn{2}{|c|}{ Characteristic } & Lost to Follow-up & Retained in care & Odd Ratio & $P$ value \\
\hline \multicolumn{2}{|c|}{$\%$ of women (n) } & $24.29(17)$ & $75.71(53)$ & & \\
\hline \multicolumn{2}{|c|}{ Age (years) } & $27.28 \pm 5.84$ & $23.75 \pm 6.69$ & & \\
\hline \multirow{2}{*}{ Religion (n) } & Christian & 6 & 42 & \multirow{2}{*}{0.15} & \multirow{2}{*}{0.001} \\
\hline & Muslim & 10 & 11 & & \\
\hline \multirow[b]{2}{*}{ Level of education ( $\mathrm{n}$ ) } & $<$ Secondary & 15 & 17 & \multirow[b]{2}{*}{31.7} & \multirow[b]{2}{*}{$<0.001$} \\
\hline & $\geq$ Secondary & 1 & 36 & & \\
\hline \multirow{2}{*}{ Marital status (n) } & Single & 2 & 16 & & \multirow{2}{*}{0.15} \\
\hline & Married & 14 & 37 & & \\
\hline \multirow[b]{2}{*}{ Profession (n) } & Housewife & 12 & 22 & \multirow{2}{*}{4.22} & \multirow[b]{2}{*}{0.01} \\
\hline & Others & 4 & 31 & & \\
\hline
\end{tabular}

Some totals may not sum up to 70,17 or 53 because of missing data.

educational level (less than secondary level) and profession (housewife) were significantly associated to the Loss to follow-up (LTFU) cases, $(p=0.01, p<$ 0.0001 and $p=0.0053$, respectively). For the retained until study endpoint, having an educational level of secondary level and above and a profession other than a housewife had a significant association $(p=0.0063)$, as well as being a Christian.

\section{Discussion}

Results of this study revealed that the most implicated route of transmission is the sexual route as we observed $73.9 \%$ participants being married. This is comparable to that obtained in a Kenyan study where $72.9 \%$ of their participants were married [13]. Our study participants were significantly housewives (52.2\%) by occupation, attended a conventional educational system (85.5\%), of at least a secondary level (53.6\%) and of the Christian faith (69.6\%) for the urban setting (Bertoua Health District). However, it is worth noting that observing an educational level of at least a secondary level at $53.6 \%$ is suboptimal for an urban setting and this is further reflected in the occupation of most participants being housewives $(52.2 \%)$ justifying their low economic level. This is similar to what was reported in the Kenyan study, with $38.3 \%$ of their participants being housewives or engaged in little businesses with an estimated mean monthly domestic expenditure of US\$102 affirming the pauperization of HIV epidemic [13] [14].

Reports from Silva et al. and other authors have shown similar observation about link between low educational levels and HIV infection [14] [15] [16] [17]. This is however contrary to studies in Spain were it was reported that $75.2 \%$ of women infected with HIV had secondary education level [18]. These can be explained by the fact that European countries have a better planning and have greatly invested in the educational system compared to what is in many 
low-income countries like in our context and Brazil [19].

We had a retention rate of $75.71 \%$ six months post ART initiation, giving a cumulative proportion of loss to follow-up at 6 months of $24.29 \%$. This is higher than what was found in a Malawi's study, were $17 \%$ of women were lost to follow-up six months after ART initiation [11] and that by Mitiku et al. in 2016, who had a LTFU rate at 6 months post ART of $11.9 \%$ [20]. This difference in rates of LTFU with what we observed may be due to the definition of LTFU case used by the different studies. We considered LTFU as a missed appointment within the study period, whereas Mitiku and co defined LTFU as 90 days since last clinic visit among those not known to have died or transferred. In a rural Ugandan study, the proportion of LTFU was $37 \%$, even far higher than what with observed [21]. Irrespective of the rate observed, it is worth noting that the occurrence of LTFU is more and more frequent with an increasing need for concern.

Taking a critical look at maternal sociodemographic characteristics at enrolment into option B+ PMTCT program in a bit to identify determinants to LTFU, we found out that maternal religion (being a Muslim) was significantly associated. Even though no study has associated maternal religion to PMTCT, we believe it is obvious, as the Muslim culture requires the male partner's approval for female's movement around with seeking for care inclusive. We also obtained as a significant associated factor, maternal educational level and occupation. Having an educational level of less than secondary level and being a housewife were statistically significant to LTFU. Kweyamba et al. (2018) also made the same observation with majority of their participants being either subsistence farmers $(56.5 \%)$, housewife $(15.6 \%)$ or causal labourer $(8.7 \%)$ as compared to professional (10.1\%) and business women (9.1\%) [21]. The educational level will not only determine the profession and living standards, but will highly affect the communication skills, understanding, interpretation of instructions and treatment compliance.

Our study did not include the clinical aspects and economic strength of our participants. Being a personally financed study, finance and time was a limiting factor to expand the sample size and follow-up time.

\section{Conclusions}

For a successful implementation of PMTCT intervention for the virtual elimination of mother-to-child transmission of HIV, maternal socio-demographic data need more consideration. Maternal socio-demographic data associated with LTFU in the option B+ include being a Muslim, with little or no education and being a housewife in addition to those reported by other authors.

\section{Acknowledgements}

We thank all study participants and staff of all the health facilities where the study took place. 


\section{Authors' Contributions}

OFM, JCNA, MRE and NNM conceived the research question and designed the study. OFM collected data and conducted laboratory assays. JCNA and MRE helped design the study question, assisted with data collection, analyzed data and assisted with data interpretation. All authors wrote and or reviewed the manuscript.

\section{Conflicts of Interest}

The authors declare no conflict of interest.

\section{References}

[1] UN Joint Programme on HIV/AIDS (UNAIDS) (2014) The Gap Report. UNAIDS, Geneva. https://www.refworld.org/docid/53f1e1604.html

[2] UN Joint Programme on HIV/AIDS (UNAIDS). The Global Report: UNAIDS Report on the Global AIDS Epidemic 2013. UNAIDS, Geneva.

[3] Joint United Nations Programme on HIV/AIDS (UNAIDS) (2019) Global AIDS Update 2019.

[4] De Cock, K.M., Fowler, M.G., Mercier, E., De Vincenzi, I., Saba, J., Hoff, E., et al. (2000) Prevention of Mother-to-Child HIV Transmission in Resource-Poor Countries: Translating Research into Policy and Practice. Journal of the American Medical Association, 283, 1175-1182. https://doi.org/10.1001/jama.283.9.1175

[5] Dorenbaum, A., Cunningham, C.K., Gelber, R.D., Culnane, M., Mofenson, L., Britto, P., et al. (2002) Two-Dose Intrapartum/Newborn Nevirapine and Standard Antiretroviral Therapy to Reduce Perinatal HIV Transmission: A Randomized Trial. $J A M A, 288,189-198$. https://doi.org/10.1001/jama.288.2.189

[6] Pisano, E., Gatsonis, C., Boineau, R., Domanski, M., Troutman, C., Anderson, J., et al. (2005) Single-Dose Perinatal Nevirapine plus Standard Zidovudine to Prevent Mother-to-Child Transmission of HIV-1 in Thailand. The New England Journal, 351, 225-237.

[7] Zaba, B., Whitworth, J., Marston, M., Nakiyingi, J., Ruberantwari, A., Urassa, M., et al. (2005) HIV and Mortality of Mothers and Children. Epidemiology, 16, 275-280. http://www.ncbi.nlm.nih.gov/pubmed/15824540 https://doi.org/10.1097/01.ede.0000155507.47884.43

[8] Newell, M.L., Coovadia, H., Cortina-Borja, M., Rollins, N., Gaillard, P. and Dabis, F. (2004) Mortality of Infected and Uninfected Infants Born to HIV-Infected Mothers in Africa: A Pooled Analysis. The Lancet, 364, 1236-1243. https://doi.org/10.1016/S0140-6736(04)17140-7

[9] Sherman, G.G., Jones, S.A., Coovadia, A.H., Urban, M.F. and Bolton, K.D. (2004) PMTCT from Research to Reality-Results from a Routine Service. South African Medical Journal, 94, 289-292. https://www.ajol.info/index.php/samj/article/view/134450

[10] Jones, S.A., Sherman, G.G. and Varga, C.A. (2005) Exploring Socio-Economic Conditions and Poor Follow-Up Rates of HIV-Exposed Infants in Johannesburg, South Africa. AIDS Care, 17, 466-470. https://doi.org/10.1080/09540120412331319723

[11] Manzi, M., Zachariah, R., Teck, R., Buhendwa, L., Kazima, J., Bakali, E., et al. (2005) High Acceptability of Voluntary Counselling and HIV-Testing But Unacceptable Loss to Follow Up in a Prevention of Mother-to-Child HIV Transmission Pro- 
gramme in Rural Malawi: Scaling-Up Requires a Different Way of Acting. Tropical Medicine \& International Health, 10, 1242-1250.

https://doi.org/10.1111/j.1365-3156.2005.01526.x

[12] Knettel, B.A., Cichowitz, C., Ngocho, J.S., Knippler, E.T., Chumba, L.N., Mmbaga, B.T., et al. (2018) Retention in HIV Care during Pregnancy and the Postpartum Period in the Option B+ Era: Systematic Review and Meta-Analysis of Studies in Africa. JAIDS Journal of Acquired Immune Deficiency Syndromes, 77, 427-438. https://www.ncbi.nlm.nih.gov/pubmed/29287029 https://doi.org/10.1097/QAI.0000000000001616

[13] Imbaya, C. and Odhiambo-Otieno, G. (2015) Socio Demographic Characteristics, Antenatal Clinic Attendance and PMTCT Knowledge of Postnatal HIV+ Women at an Urban Public Health Facility in Nairobi, Kenya. The East and Central Africa Medical Journal, 2, 10-17. http://etd-library.ku.ac.ke/handle/123456789/13070

[14] Silva, C.M., Alves, R.S., Santos, T.S., Bragagnollo, G.R., Tavares, C.M. and Santos, A.A.P. (2018) Epidemiological Overview of HIV/AIDS in Pregnant Women from a State of Northeastern Brazil. Revista Brasileira de Enfermagem, 71, 568-576. https://doi.org/10.1590/0034-7167-2017-0495

[15] Langendorf, F., Padoin, D.M., Maris, S., Vieira, B. and Mutti, F. (2011) Gestantes que tem HIV/AIDS no contexto da transmissão vertical: visibilidade da produçãocientificanacionalnaárea da saúde. Revista de Pesquisa Cuidado é Fundamental Online, 3, 2109-2125.

[16] Souza, C.D.P., Piantino, C.B., Queiroz, C.A., Maia, M.A.C., Fortuna, C.M. and Andrade, R.D. (2016) Regional Incidence of HIV Vertical Transmission among HIV-Positive Pregnant Women Treated at a Regional Reference Service. Revista de Pesquisa: Cuidado é Fundamental Online, 8, 4526. https://doi.org/10.9789/2175-5361.2016.v8i2.4526-4537

[17] Konopka, C.K., Beck, S.T., Wiggers, D., Silva, A.K., Diehl, F.P. and Santos, F.G. (2010) Perfilclínico e epidemiológico de gestantesinfectadaspelo HIV em um serviço do sul do Brasil. Revista Brasileira de Ginecologia e Obstetrícia, 32, 184-190. http://www.scielo.br/scielo.php?script=sci_arttext\&pid=S0100-72032010000400006 \&lng=pt\&nrm=iso\&tlng $=\mathrm{pt}$ https://doi.org/10.1590/S0100-72032010000400006

[18] Hernando, V., Alejos, B., Montero, M., Pérez-Elias, M., Blanco, J.R., Giner, L., et al. (2017) Reproductive History before and after HIV Diagnosis: A Cross-Sectional Study in HIV-Positive Women in Spain. Medicine (United States), 96, 1-7. https://doi.org/10.1097/MD.0000000000005991

[19] Giffin, K. and Costa, S.H. (1999) Questões da saúdereprodutiva [Internet]. Editora Fiocruz. http://books.scielo.org/id/t4s9t https://doi.org/10.7476/9788575412916

[20] Mitiku, I., Arefayne, M., Mesfin, Y. and Gizaw, M. (2016) Factors Associated with Loss to Follow-Up among Women in Option B+ PMTCT Programme in Northeast Ethiopia: A Retrospective Cohort Study. Journal of the International AIDS Society, 19, 1-8. https://doi.org/10.7448/IAS.19.1.20662

[21] Kweyamba, M., Buregyeya, E., Kusiima, J., Kweyamba, V. and Mukose, A.D. (2018) Loss to Follow-Up among HIV Positive Pregnant and Lactating Mothers on Lifelong Antiretroviral Therapy for PMTCT in Rural Uganda. Advances in Public Health, 2018, 1-9. https://doi.org/10.1155/2018/7540587 


\section{Appendix 1: Research Questionnaire}

Topic: The Effect of Highly Active Anti-retroviral therapy (HAART) on Maternal Viral Load and 6 weeks Infant PCR Status

Research Code \#:

1. Demographic Characteristics
a) Age:
b) Address:
c) Occupation:
d) Level of education: 1
e) Religion: Christian
$\square$
$2^{\circ}$
Arabic School
f) Marital status: Single
Muslim
$3^{\circ} \square$
Atheist $\square$
None
Married $\square$

\section{Clinical Data/ History}

a) Weight: __ b) Temperature:

c) BP:

d) Gravidity

e) Presumed delivery date:

f) Parity:

g) Foetal parameters:

h) Date Diagnosed of HIV:

i) Date of Initiation on ARV:

j) Has participant received any antiviral vaccine during the past 3 months?: Yes or No

If yes, which?

k) Is participant on any medication (s)? Yes or $\mathrm{No}$ , and when? If yes, specify For how long?

1) Transfusion History: Yes___ or No___. When:

\section{Laboratory Findings}

\begin{tabular}{|l|l|l|l|l|}
\hline Date & Test done & Result/ Test value & Unit of measurement & Inference (Remark) \\
\hline & HIV (ELISA) & & & \\
\hline & Viral load, $\mathrm{T}_{0}$ & & Copies/ml & \\
\hline & ASAT & & & \\
\hline & ALAT & & & \\
\hline & Creatinine & & & \\
\hline & Malaria test & & & \\
\hline & Urinalysis & & & \\
\hline & VDRL/TPHA & & & \\
\hline
\end{tabular}

b) Hepatitis Screening: Hepatitis B (HBsAg):Reactive : Non-reactive

Hepatitis C (antiHCAb): Reactive : Non-reactive 


\section{Appendix 2: Research Follow-Up Sheet}

Topic: The Effect of Highly Active Anti-retroviral therapy (HAART) on Maternal Viral Load and 6 weeks Infant PCR Status

RDV (CPN) No:

Research Code \#:

Date:

Next RDV:

\section{Clinical and Obstetrical Data}

a) Weight:

b) Temperature:

c) BP:

d) Uterine Height

e) Abdominal Circumference:

f) Foetal Heart Beat:

g) Has participant been recently hospitalized?: Yes or No If yes, diagnosed? and when?

h) Is participant on any medication (s)? Yes or No If yes, specify For how long?

i) Anti-Tetanus vaccine History: Yes When:

j) Partner's HIV status: Unknown $\square$ Known $\square$. If known, results: Negative $\square$ Positive

k) Sexual activeness: Inactive $\square \quad$ Active with condom $\square \quad$ Active without condom

1) Other complains and/or observations? Yes $\square$ No $\square$. If yes, specify:

\section{HAART Observance}

a) How many times have you forgotten to take your treatment within the past 4 days?

None $\square \quad$ Once $\square \quad$ Twice $\square \quad$ Thrice $\square \quad$ 4X $\square>4 X \square$

b) Was HAART taken on time from the pharmacy? Yes $\square$ No $\square$

c) Is RDV respected? Yes $\square$ No $\square$

3. LaboratoryFindings

\begin{tabular}{|l|l|l|l|l|}
\hline Date & Test done & Result/ Test value & Unit of measurement & Inference (Remark) \\
\hline & Viral load, & & Copies/ml & \\
\hline & ASAT & & & \\
\hline & ALAT & & & \\
\hline & Creatinine & & & \\
\hline & Malaria test & & & \\
\hline & Urinalysis & & & \\
\hline & FBC/HB & & & \\
\hline
\end{tabular}

